\title{
Programmed cell delivery from biodegradable microcapsules for tissue repair
}

\author{
L. Draghi ${ }^{\mathrm{a}}$, D. Brunelli ${ }^{\mathrm{b}}, \mathrm{S}$. Farè and M.C. Tanzi ${ }^{\mathrm{a}}$ \\ ${ }^{a}$ Chemistry, Materials and Chemical Engineering Departntent "G. Natta", Politecnico di Milano, \\ Piazza Leonardo da Vinci, 32 - 20133, Milano, Italy; ${ }^{b}$ Politecnico di Milano, Piazza Leonardo \\ da Vinci, 32 - 20133, Milano, Italy
}

(Received 9 January 2015; accepted 1 July 2015)

\section{Introduction}

In its most typical configuration, the design of a tissue engineering construct involves a scaffold material to fill the defect, support and guide cells and possibly offer specific biological cues. Compared to pre-shaped porous biomaterials, an injectable scaffold offers two major advantages, namely the minimally invasive procedure required for delivery and the ability to conform to defect volume and shape, avoiding the need for custom manufacturing. Furthermore, growth factors and cell adhesion ligands can easily be incorporated to sustain tissue formation.

However, the design of injectable materials introduces an additional entry to the already long list of biomaterial requirements.[1] A low viscosity solution is, in fact,

*Corresponding author. Email: lorenza.draghi@polimi.it 
required for suspending the cell population in an injectable carrier, and the solidification process must of course be compatible with cell survival. In situ polymerization, crosslinking or gelation must therefore occur under extremely mild conditions, which significantly limits the number of suitable formulations. Injectable systems based on either synthetic or natural polymers have been proposed for a variety of applications,[2-10] though primarily for cartilage, bone and myocardium tissue engineering.[11-21] Natural polymers have attracted the majority of research efforts, mainly because of their physiologically mild gelation conditions, but also because it is possible for them to play an active role in cell adhesion and remodelling. Accordingly, different examples of protein- (e.g. fibrin, gelatine and heparin) and polysaccharide- (e.g. hyaluronan, chitosan, alginic acid) based gellable systems were reported.

Unlike preformed scaffolds, injectable gels generally possess only a nanoscale porosity, so that a critical factor is undoubtedly represented by mass transport phenomena. Inadequate diffusion of gases, nutrients, waste products and biological signalling molecules within the gel impairs cell survival in inner material portions and hampers tissue regeneration.[22]

To overcome this limitation, various methods of fabricating porous injectable scaffolds have been proposed, including in situ pore formation by phase separation and particulate leaching. $[23,24]$ A different strategy to avoid excessive mass transportrelated drawbacks might also be represented by injection of cells loaded in rapidly degradable hydrogel microcapsules. The reduced microcapsule dimensions still permit delivery by injection, but the maximum material thickness between a cell and the host environment is limited to sphere radius.

Cell microencapsulation is a well-established technique in cell therapy in which medium-term biostable materials are employed as membranes to protect non-autologous secretory cells from the host's immune system. The most advanced research topic in this area is grafting of pancreatic cells for glycemic control in diabetic recipients, since microencapsulation can reduce or eliminate the need for immunosuppressive therapy required by simple islet transplantation.

Although a few synthetic polymers have also been proposed,[25] natural polymers have mainly been considered for cell microencapsulation. Alginate-based hydrogels, in particular, have been the subject of extensive research for their good cell compatibility, relatively long-term stability and, above all, their unique and extremely mild ioninduced gelation mechanism.[26]

Alginates collectively indicates a family of naturally occurring polysaccharides composed of $\beta$-D-mannuronic acid (M) and $\alpha$-L-guluronic acid $(G)$ homoblock and alternating block in varying proportions and lengths. Upon interaction with divalent metal ions, an ordered structure, the so-called egg-box, is formed and was shown to involve cooperative binding of calcium ions between blocks of guluronic acid residues in two alginate chains.[27]

The most widely studied alginate-based formulations involve complexation with polycations, poly-L-lysine and chitosan in particular, to control permeability and increase strength and stability.[28-30] Nevertheless, other, different alginate-based formulations have been examined over the years to further improve the effectiveness of cell encapsulation, including cross-linked alginate-gelatine,[31] alginate-poly(ethylene glycol),[32] or alginate and hyaluronic acid stabilized with polyethyleneimine.[33]

Together with alginate, different biopolymers capable of gelling under mild conditions have attracted attention as cell carriers. Agarose gelation, for example, can be temperature-induced [34] and agarose alone or mixed with collagen has been 
demonstrated to allow preparation of microbeads under conditions compatible with cell survival.[35,36] Collagen, type I in particular, can also be thermally gellated to prepare microcapsules containing viable cells [37] although, despite great interest due to its high biocompatibility, enzymatic in vivo degradation has often represented an obstacle for cell therapy applications.

Where the majority of formulas proposed in past years for microencapsulation were intended to increase material stability and support localized controlled cell release, long-term permanence of microcapsules ceases to be a requirement. On the contrary, to achieve retention and programmable release of viable cells in the regenerating tissue, the degradation rate of the microcapsule should be controllable.

The possibility of controlling microcapsule breakdown rate for alginate-based hydrogels by acting on their composition was explored here, and cell viability and release from microcapsules was assessed in vitro.

\section{Materials and methods}

\subsection{Hydrogel formulations}

All hydrogel formulations were based on sodium alginate (alginic acid sodium salt from brown algae, viscosity 100-300 cp, Sigma) and cross-linking was obtained by dripping alginate in a beaker containing a calcium chloride solution.

Plain alginate hydrogels were prepared with sodium alginate dissolved $1-2 \% \mathrm{w} / \mathrm{v}$ in deionizied water and using calcium chloride concentrations ranging from 0.05 to $0.25 \mathrm{M}$. Mixed formulations were prepared by adding either thermo-reversible gel forming poloxamer (Lutrol ${ }^{\circledR} \mathrm{F} 127, \mathrm{BASF}$ ) to alginate solution or $0.2 \% \mathrm{w} / \mathrm{v}$ weight chi-tosan (low molecular weight chitosan, Sigma, $75-85 \%$ deacetylated) to a calcium chlo-ride solution, to reduce or increase microsphere degradation time, respectively. While positively charged chitosan is known to strengthen alginate cross-linking,[29,30] polox-amer was chosen for its reduced stability together with its mild, temperature controlled, gel forming mechanism. When poloxamer was added, alginate solution was cooled down to $-8{ }^{\circ} \mathrm{C}$ before dripping and calcium chloride solution was heated to $37^{\circ} \mathrm{C}$ on a heating plate.

\subsection{Fabrication and morphological characterization of microcapsules}

Microcapsules were produced using a simple coaxial airflow dripping system similar to others previously described,[38] illustrated in Figure 1. The influence of process parameters (syringe pumps flow, air pressure and syringe needle gauge) was assessed in preliminary experiments and is briefly reported in Section 3.1. The morphology of microcapsules was evaluated on a dissecting microscope equipped with a CCD camera, and images were acquired to calculate bead diameter as the average length of two perpendicular axes for 20 randomly selected beads and eccentricity as their ratio.

\subsection{Evaluation of hydrogel stability}

The swelling and weight loss of microspheres were evaluated after ageing in a phos-phate buffered saline at $37 \pm 1{ }^{\circ} \mathrm{C}$ for up to five weeks to appraise their kinetics. To measure weight variation, microspheres were strained from PBS and centrifuged to eliminate excess water. 


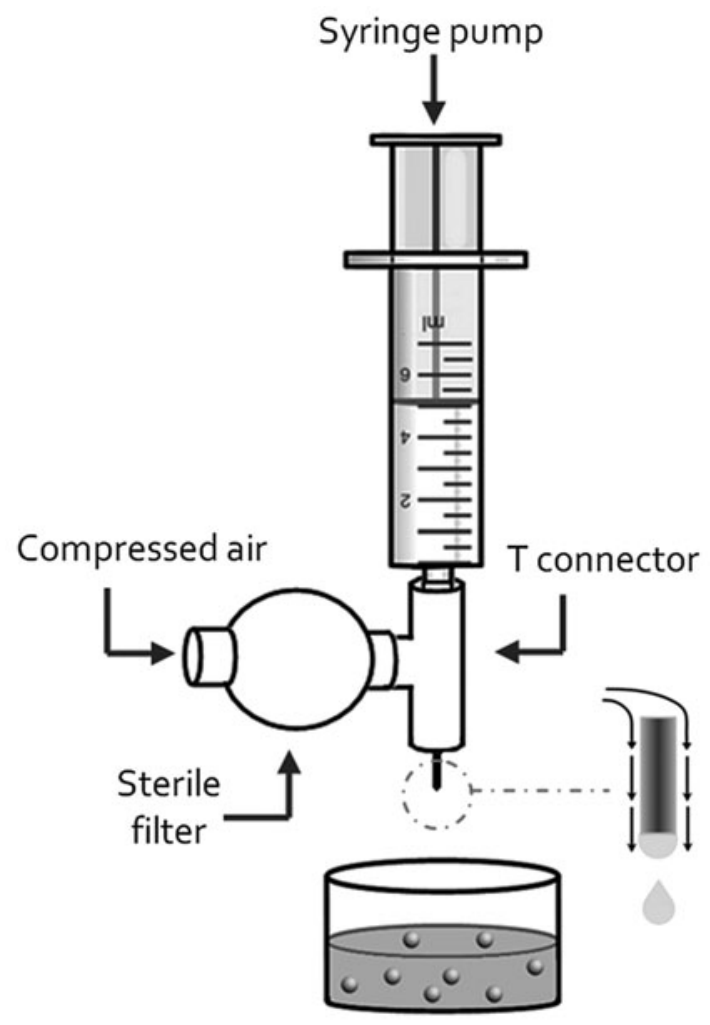

Figure 1. Coaxial flow dripping apparatus design scheme.

The macroscopic appearance of capsules throughout the degradation period was assessed for largest diameter microcapsules, aged in vitro under the same conditions, by acquiring images with a digital camera equipped with a macro lens.

\subsection{Cell encapsulation}

For cell encapsulation experiments, $1.5 \% \mathrm{w} / \mathrm{v}$ alginate and $0.15 \mathrm{M}$ calcium chloride hydrogels were prepared using Dulbecco's modified Eagle's medium (DMEM) for dissolving alginate. For mixed formulations, poloxamer was added $20 \% \mathrm{v} / \mathrm{w}$ to an alginate solution and chitosan $0.2 \% \mathrm{v} / \mathrm{w}$ to calcium chloride. Mouse myoblast $\mathrm{C} 2 \mathrm{C} 12$ cells were detached from flasks with trypsin-EDTA when reaching $50 \%$ confluence and resuspended $\left(0.9 \times 10^{6}\right.$ cells $\left./ \mathrm{mL}\right)$ in alginate or an ice-cold alginate/poloxamer solution to prepare microcapsules. Cell-loaded microcapsules were then collected from the calcium chloride bath and distributed in 6-well plates containing DMEM supplemented with $10 \%$ foetal calf serum and $1 \%$ penicillin/streptomycin. A sample of microcapsules for each material formulation was extracted and incubated with excess fluorescein diacetate dye to evaluate cell survival of the encapsulation process. The remaining microcapsules were transferred to a cell incubator $\left(37^{\circ} \mathrm{C}, 5 \% \mathrm{CO}_{2}\right)$ and examined daily to record the cells' fate. The number of cells released by the microcapsules was estimated by acquiring microscopic images of the well bottom for each formulation and by counting cells in five randomly selected square areas $(0.25 \mathrm{~mm}$ per side). 


\section{Results and discussion}

\subsection{Fabrication of microcapsules}

The coaxial airflow dripping apparatus was confirmed to be an extremely simple and effective method for preparing microcapsules and controlling their size. As shown in Figure 2 , by acting on air pressure regulation $(p=0.25-0.5 \mathrm{~atm})$, bead diameter could easily be controlled (Figure 2) and a significant difference ( $p<0.05$ from Student's $t$-test) among all the needle diameters considered was found. Conversely, large differences in needle diameter were required to reveal an appreciable variation in microsphere dimension (only 16 vs. $22 \mathrm{G}$ had $p<0.05$ ) and syringe pump flow (influ-ence appeared negligible ( $p>$ 0.05 for $10 \mathrm{vs.} 50 \mathrm{ml} / \mathrm{h}$ ) within reasonable values. For all material formula, eccentricity values were found to be very close to 1 , indicating that capsule shape was spherical with good approximation (data not shown).

\subsection{Swelling and destabilization behaviour}

As reasonably expected, destabilization of pure alginate microspheres was influenced by both sodium alginate and calcium chloride concentrations. When looking at bead appearance after ageing in PBS (Figure 3), it may be observed that microcapsule breakdown
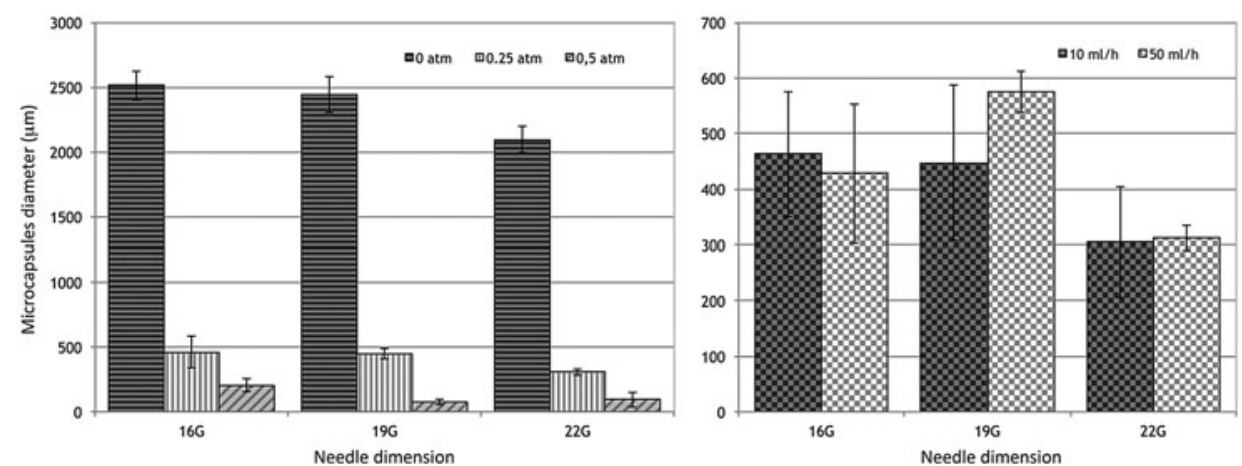

Figure 2. Influence of airflow pressure $(0 \div 0.5 \mathrm{~atm})$, syringe pump flow $(10-50 \mathrm{ml} / \mathrm{hr})$ and needle diameter on alginate microcapsules diameter.
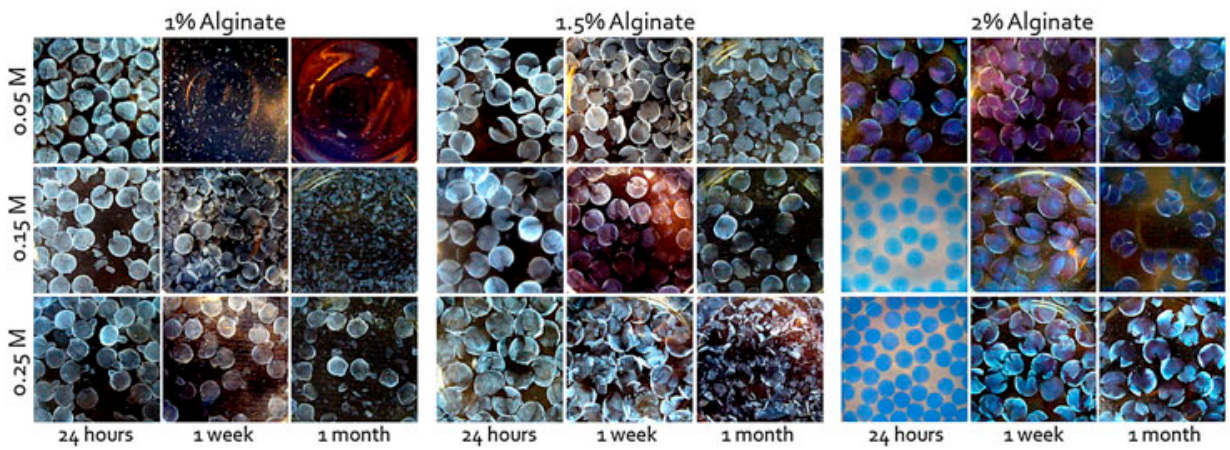

Figure 3. Macroscopic appearance of plain alginate microspheres after ageing in PBS. 
was almost complete in one week for $1 \%$ alginate $0.05 \mathrm{M}$ calcium, while beads were still distinguishable after one month when molarity was raised to 0.25 . The effect of raising calcium concentration was not similarly straightforward for 1.5 and $2 \%$ alginate beads. For $1.5 \%$ capsules in particular, superior stability was observed for the intermediate calcium molarity. Persistence of $2 \%$ alginate capsules was observed for all calcium molarities, and very low swelling after $24 \mathrm{~h}$ was qualitatively detected for 0.15 and $0.25 \mathrm{M}$ beads. Furthermore, shell cracking after one week was found to be more severe than in other alginate concentrations.

When assessing weight variation of microcapsules in PBS (Figure 4), degrees of swelling of up to $190 \%$ were observed. For different alginate concentrations (left in Figure 4), weight variations seem to be in accordance with the appearance shown in Figure 3. Rapid weight loss was found after 1 week for $1 \%$ alginate, while higher stability was observed for 1.5 and $2 \%$. The slower water uptake found for $2 \%$ alginate was also reflected in capsule appearance and is in accordance with previous experiments that found a linear trend among delay in swelling and alginate concentra-tion varying from 1 to 3\%.[39]

While examining the effect of calcium for $1.5 \%$ alginate compositions (left in Figure 4), the weight trend appears to be in accordance with early breakdown of capsules for $0.15 \mathrm{M}$ formulations, while very little difference was found between 0.15 and $0.25 \mathrm{M}$ calcium beads.

Swelling and breakdown of alginate microcapsules in phosphate buffered saline (PBS) are explained by an ion-exchange mechanism between $\mathrm{Ca}^{2+}$ and $\mathrm{Na}^{+}$ions available in the ageing solution. In the initial stage, ion-exchange involves mainly $\mathrm{Ca}^{2+}$ ions in polymannuronate blocks and results in a weaker structure that accounts for observed water uptake. In the later stages, $\mathrm{Ca}^{2+}$ ions in egg-box polyguluronate blocks start to diffuse out and beads begin to dissolve and lose weight.[40] On increasing sodium alginate concentration when beads are formed, a higher number of binding sites are available for diffusing $\mathrm{Ca}^{2+}$ ions and, as a result, a more densely cross-linked (and less thick) membrane is formed for a given gelation time.[39,41] Denser shell initially hinders diffusion phenomena, and this might explains the delayed swelling for higher alginate concentrations. Furthermore, densely cross-linked shells are more rigid and possibly less capable of sustaining deformation caused by water uptake, accounting for the numerous shell breaks observed for $2 \%$ formulations. On the other hand, when cross-linking solution with higher calcium molarities is used, the greater gradient allows
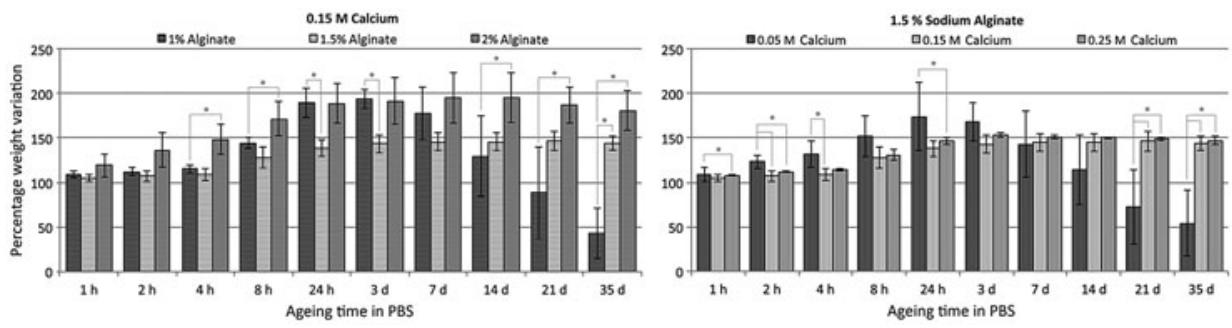

Figure 4. Percent weight variation after ageing in PBS for microcapsules prepared with alginate alone with different sodium alginate concentration (left, $p<0.05$ from Student's $t$-test where indicated by star and for all timepoints after $1 \mathrm{~h}$ for 1.5 vs. $2 \%$ ) and calcium molarity (right, $p<0.05$ where indicated). 


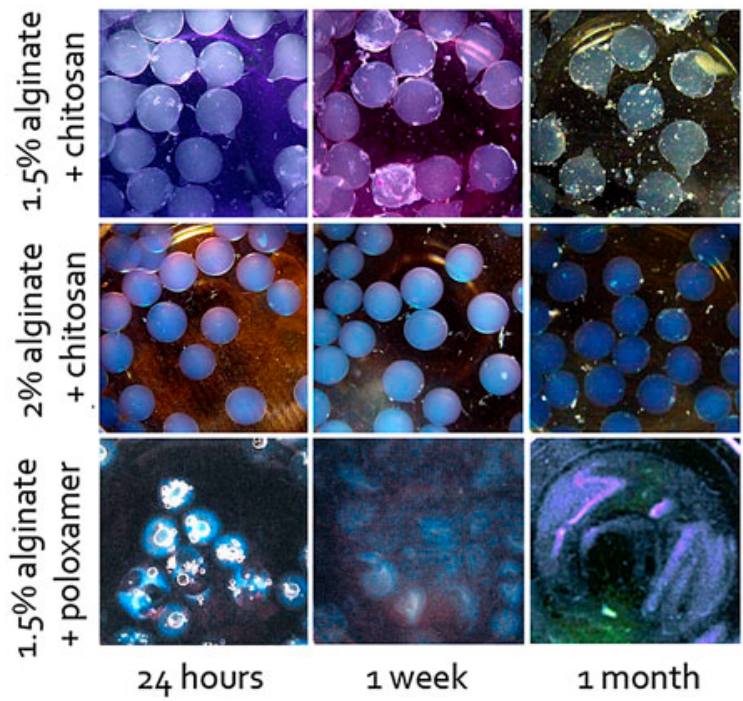

Figure 5. Macroscopic appearance of $1.5 \%$ alginate microcapsules prepared with $20 \%$ poloxamer and $0.2 \%$ chitosan after ageing in PBS.

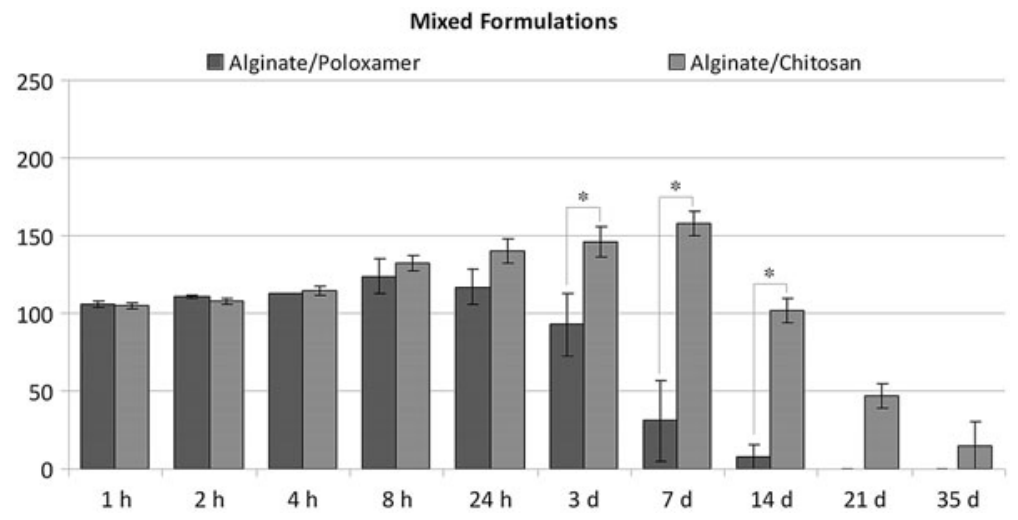

Figure 6. Percentage weight variation for $20 \%$ poloxamer and $0.2 \%$ chitosan microcapsules after ageing in PBS. $p<0.05$ from Student's $t$-test where indicated by star.

for deeper penetration of calcium ions towards the centre of the forming bead, which will therefore result more homogeneous. A more cross-linked core might thereby possess superior stability, and persist even after shell rupture.

The addition of poloxamer and chitosan was also found to influence microcapsule swelling and degradation behaviour (Figures 5 and 6). By mixing poloxamer with the alginate solution, the destabilization rate increased significantly, and breakdown of capsules was almost complete by two weeks. On the contrary, chitosan microspheres appeared to be almost unaltered, with no visible signs of capsule cracking after one month. When poloxamer and chitosan formula weight loss was taken into considera-tion, rapid destabilization of poloxamer beads was confirmed, while weight loss was 
faster than expected in capsules prepared with chitosan. This contradiction can be at least partially explained on the basis of the different capsule dimensions, since images were acquired for capsules with larger diameters than the beads used for weight loss and encapsulation experiments. It was previously observed that mechanical properties of alginate/chitosan microspheres generally increase with reduction in diameter, but below 300 micrometres this trend is reversed and small capsules appear weaker than slightly larger microspheres.[29]

\subsection{Cell encapsulation}

Fluorescein diacetate was able to penetrate the capsule shell, and staining effectively permitted visualization of the presence of viable cells within the microspheres for all the formulations tested (Figure 7). After 3 days in culture, cells released from poloxamer
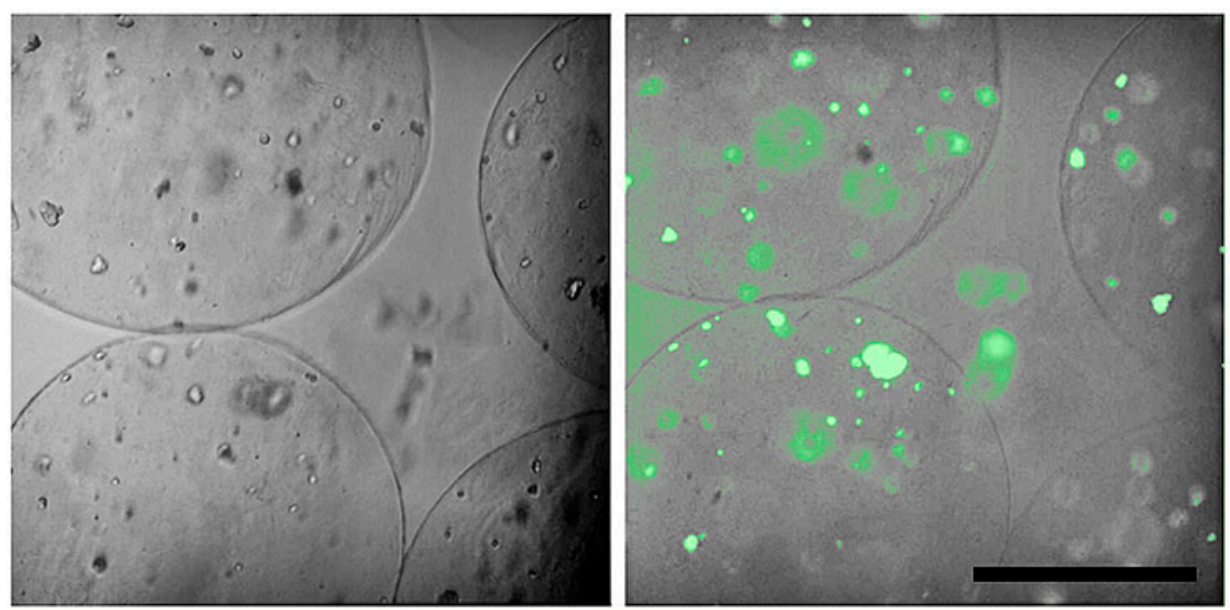

Figure 7. Fluorescein diacetate staining of cell loaded $1.5 \% \mathrm{w} / \mathrm{v}$ alginate and $0.15 \mathrm{M}$ calcium chloride microcapsules with (right) or without fluorescent filter (left). Scale bar $=500$ micrometres.
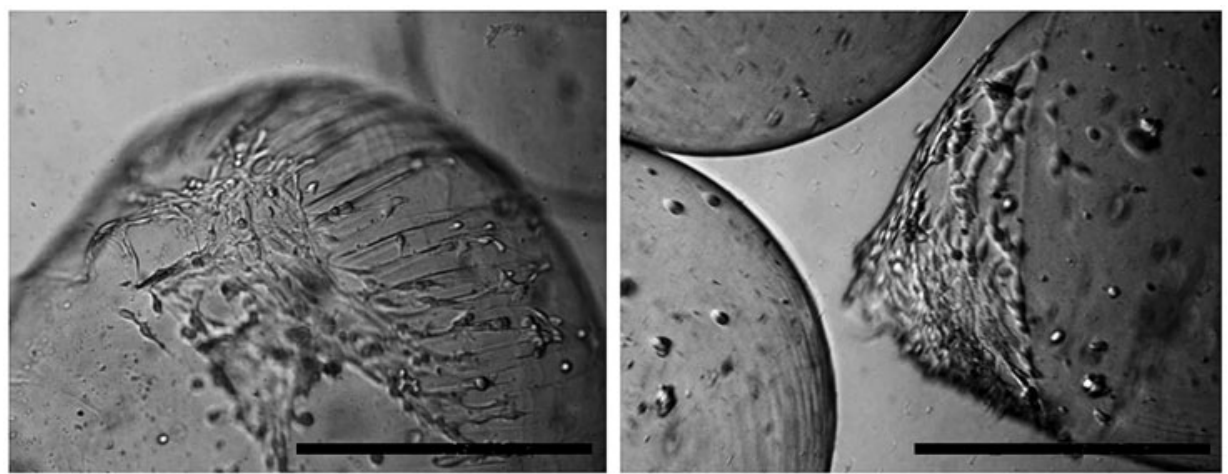

Figure 8. Appearance of cells in $1.5 \% \mathrm{w} / \mathrm{v}$ alginate and $0.15 \mathrm{M}$ calcium chloride microcapsules after two weeks. Scale bar $=200$ micrometres. 


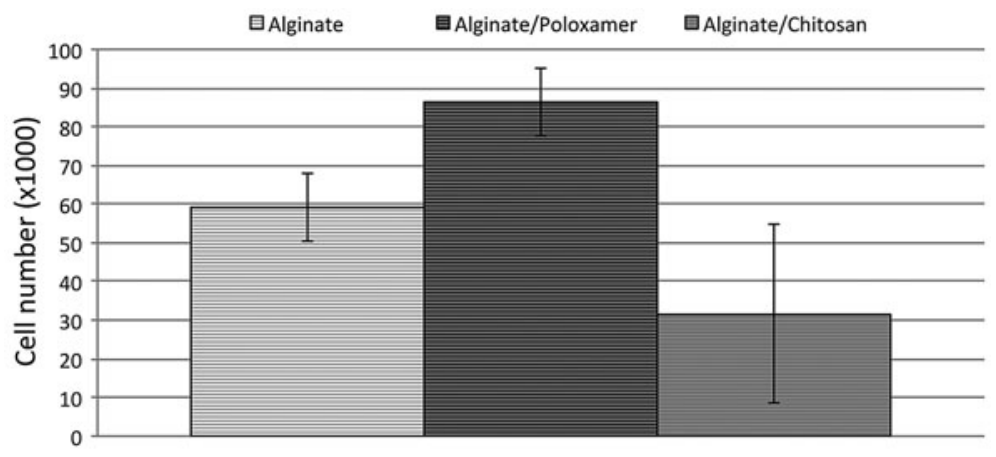

Figure 9. Number of cells on the bottom of wells containing microcapsules for $1.5 \%$ alginate $0.15 \mathrm{M}$ calcium, alginate/poloxamer and alginate-chitosan microcapsules $(p<0.05$ from Student's $t$-test for all paired comparisons). For poloxamer microcapsules, cells were confluent.

containing microcapsules were observed on the well bottom, while one week was necessary to find released cells for plain alginate and alginate-chitosan formulations. For the latter two, upon capsule breakage, cells were found to be prevalently growing in the space between the capsule's external shell and its softer inner core (Figure 8). After 14 days, well observation showed significant differences in cell density for the 3 formulation tested (Figure 9), supporting the hypothesis that simple changes in material formulas permit control of bead breakdown rate, achieving programmed cell release from alginate-based microcapsules.

\section{Conclusions}

When injectable materials are considered, the presence of cells during gelation significantly reduces the number of suitable chemistries. Due to the high biocompatibility of both precursors and degradation products and the extremely mild gelation conditions, naturally occurring hydrogels often appear to be the ideal choice for encapsulation, although they are generally lacking in terms of properties tunability. For alginate-based formulations, controlling calcium ion and sodium alginate concentrations and mixing with other natural or synthetic polymers offers a simple solution for adjusting bead destabilization according to the envisaged application and regulating cell release.

Rapidly degradable microcapsules have the potential to preserve the benefits of injectable materials, i.e. maintain defect volume and localize and enhance the therapeu-tic effect of cell delivery, but with reduced limitations in terms of diffusion. Further-more, provided that alginate itself is not capable of specific interactions with cells, [42] proteins (e.g. fibrinogen [43]), peptides or other biologically active molecules can be introduced not only to influence material stability, but also to improve alginate biocompatibility and promote interactions between hydrogel and encapsulated cells by presenting specific chemical cues.

\section{Disclosure statement}

No potential conflict of interest was reported by the authors. 


\section{References}

[1] Ratner BD, Hoffman AS, Schoen FJ, Lemons JE. Biomaterials science: an introduction to materials in medicine 2nd Ed. San Diego (CA): Elsevier Academic Press; 2004.

[2] Anseth KS, Metters AT, Bryant SJ, Martens PJ, Elisseeff JH, Bowman CN. In situ forming degradable networks and their application in tissue engineering and drug delivery. J. Controlled Release. 2002;78:199-209.

[3] Lee KY, Mooney DJ. Hydrogels for tissue engineering. Chem. Rev. 2001;101:1869-1880.

[4] Hou QP, De Bank PA, Shakesheff KM. Injectable scaffolds for tissue regeneration. J. Mater. Chem. 2004;14:1915-1923.

[5] Nicodemus GD, Bryant SJ. Cell encapsulation in biodegradable hydrogels for tissue engineering applications. Tissue Eng. 2008;14:149-165.

[6] Yu L, Ding J. Injectable hydrogels as unique biomedical materials. Chem. Soc. Rev. 2008;37:1473-1481.

[7] Balakrishnan B, Jayakrishnan A. Self-cross-linking biopolymers as injectable in situ forming biodegradable scaffolds. Biomaterials. 2005;26:3941-3951.

[8] Sharifi S, Imani M, Mirzadeh H, Atai M, Ziaee F, Bakhshi R. Synthesis, characterization, and biocompatibility of novel injectable, biodegradable, and in situ crosslinkable polycarbonate-based macromers. J. Biomed. Mater. Res. A. 2009;90A:830-843.

[9] Cho MH, Kim KS, Ahn HH, et al. Chitosan gel as an in situ-forming scaffold for rat bone marrow mesenchymal stem cells in vivo. Tissue Eng. Part A. 2008;14:1099-1108.

[10] Hou Q, De Bank PA, Shakesheff KM. Injectable scaffolds for tissue regeneration. J. Mater. Chem. 2004;14:1915-1923.

[11] Lu L, Zhu X, Valenzuela RG, Currier BL, Yaszemski MJ. Biodegradable polymer scaffolds for cartilage tissue engineering. Clin. Orthop. Relat. Res. 2001;391:S251-S270.

[12] Dobratz EJ, Kim SW, Voglewede A, Park SS. Injectable cartilage: using alginate and human chondrocytes. Arch. Facial Plast. Surg. 2009;11:40-47.

[13] Bensaïd W, Triffitt JT, Blanchat C, Oudina K, Sedel L, Petite H. A biodegradable fibrin scaffold for mesenchymal stem cell transplantation. Biomaterials. 2003;24:2497-2502.

[14] Christman KL, Fok HH, Sievers RE, Fang Q, Lee RJ. Fibrin glue alone and skeletal myoblasts in a fibrin scaffold preserve cardiac function after myocardial infarction. Tissue Eng. 2004;10:403-409.

[15] Sittinger M, Hutmacher DW, Risbud MV. Current strategies for cell delivery in cartilage and bone regeneration. Curr. Opin. Biotechnol. 2004;15:411-418.

[16] Elisseeff J. Injectable cartilage tissue engineering. Expert Opin. Biol. Ther. 2004;4:1849-1859.

[17] Bonzani IC, Adhikari R, Houshyar S, Mayadunne R, Gunatillake P, Stevens MM. Synthesis of two-component injectable polyurethanes for bone tissue engineering. Biomaterials. 2007;28:423-433.

[18] Park KH, Na K. Effect of growth factors on chondrogenic differentiation of rabbit mesenchymal cells embedded in injectable hydrogels. J. Biosci. Bioeng. 2008;106:74-79.

[19] Okabe K, Yamada Y, Ito K, Kohgo T, Yoshimi R, Ueda M. Injectable soft-tissue augmentation by tissue engineering and regenerative medicine with human mesenchymal stromal cells, platelet-rich plasma and hyaluronic acid scaffolds. Cytotherapy. 2009;11:307-316.

[20] Yang X, Li X. Nucleus pulposus tissue engineering: a brief review. Eur. Spine. J. $2009 ; 18: 1564-1572$.

[21] Singelyn JM, DeQuach JA, Christman KL. Injectable myocardial matrix as a scaffold for myocardial tissue engineering. Conf. Proc. IEEE Eng. Med. Biol. Soc. 2009;2406-2408.

[22] Drury JL, Mooney DJ. Hydrogels for tissue engineering: scaffold design variables and applications. Biomaterials. 2003;24:4337-4351.

[23] Jeon O, Krebs M, Alsberg E. Controlled and sustained gene delivery from injectable, porous PLGA scaffolds. J. Biomed. Mater. Res. A. 2011;98A:72-79.

[24] Krebs MD, Sutter KA, Lin AS, Guldberg RE, Alsberg E. Injectable poly(lactic-co-glycolic) acid scaffolds with in situ pore formation for tissue engineering. Acta Biomater. 2009;5: $2847-2859$.

[25] de Vos P, Lazarjani HA, Poncelet D, Faas MM. Polymers in cell encapsulation from an enveloped cell perspective. Adv. Drug Deliv. Rev. 2014;67-68:15-34.

[26] Lim F, Moss RD. Microencapsulation of living cells and tissues. J. Pharm. Sci. 1981;70: 351-354. 
[27] Grant GT, Morris ER, Rees DA, Smith PJC, Thom D. Biological interactions between polysaccharides and divalent cations: the egg-box model. FEBS Lett. 1973;32:195-198.

[28] Thakur A, Sengupta R, Matsui H, Lillicrap D, Jones K, Hortelano G. Characterization of viability and proliferation of alginate-poly-L-lysine-alginate encapsulated myoblasts using flow cytometry. J. Biomed. Mater. Res. B Appl. Biomater. 2010;94:296-304.

[29] Baruch L, Machluf M. Alginate-chitosan complex coacervation for cell encapsulation: effect on mechanical properties and on long-term viability. Biopolymers. 2006;82(6):570-579.

[30] Gåserød O, Sannes A, Skjåk-Braek G. Microcapsules of alginate-chitosan. II. A study of capsule stability and permeability. Biomaterials. 1999;20:773-783.

[31] Sarker B, Papageorgiou DG, Silva R, et al. Fabrication of alginate-gelatin crosslinked hydrogel microcapsules and evaluation of the microstructure and physico-chemical properties. J. Mater. Chem. B. 2014;2:1470-1482.

[32] Mahou R, Meier RPH, Bühler LH, Wandrey C. Alginate-poly(ethylene glycol) hybrid microspheres for primary cell microencapsulation. Materials. 2014;7:275-286.

[33] Rajaram A, Schreyer DJ, Chen DX. Use of the polycation polyethyleneimine to improve the physical properties of alginate-hyaluronic acid hydrogel during fabrication of tissue repair scaffolds. J. Biomater. Sci., Polym. Ed. 2015;26:433-445.

[34] Gin H, Dupuy B, Baquey C, Ducassou D, Aurertin J. Agarose encapsulation of islets of Langerhans: reduced toxicity in vitro. J. Microencapsul. 1987;4:239-242.

[35] Jain K, Yang H, Cai BR, et al. Retrievable, replaceable, macroencapsulated pancreatic islet xenografts. Long-term engraftment without immunosuppression. Transplantation. 1995;59: 319-324.

[36] Jain K, Yang H, Asina SK, et al. Long-term preservation of islets of Langerhans in hydrophilic macrobeads. Transplantation. 1996;61:532-536.

[37] Huang SB, Chang YH, Lee HC, Tsai SW, Wu MH. A pneumatically-driven microfluidic system for size-tunable generation of uniform cell-encapsulating collagen microbeads with the ultrastructure similar to native collagen. Biomed. Microdevices. 2014;16:345-354.

[38] Ning GB, Guo MZ. Design and application study of cell microcapsulation instrument. Chin. J. Biotechnol. 1989;5:97-104.

[39] Therdphapiyanak N, Jaturanpinyo M, Waranuch N, Kongkaneramit L, Sarisuta N. Development and assessment of tyrosinase inhibitory activity of liposomes of Asparagus racemosus extracts. Asian J. Pharm. Sci. 2013;8:134-142.

[40] Bajpai SK, Sharma S. Investigation of swelling/degradation behaviour of alginate beads crosslinked with $\mathrm{Ca}^{2+}$ and $\mathrm{Ba}^{2+}$ ions. React. Funct. Polym. 2004;59:129-140.

[41] Blandino A, Macías M, Cantero D. Formation of calcium alginate gel capsules: influence of sodium alginate and $\mathrm{CaCl}_{2}$ concentration on gelation kinetics. J. Bioscie. Bioeng. 1999; 88:686-689.

[42] Rowley JA, Madlambayan G, Mooney DJ. Alginate hydrogels as synthetic extracellular matrix materials. Biomaterials. 1999;20:45-53.

[43] Liu J, Zhou H, Weir MD, Xu HH, Chen Q, Trotman CA. Fast-degradable microbeads encapsulating human umbilical cord stem cells in alginate for muscle tissue engineering. Tissue Eng. Part A. 2012;18:2303-2314. 